\title{
Erratum to: The survival of patients with high grade glioma from different ethnic groups in South East England
}

\author{
T. Ratneswaren $\cdot$ R. H. Jack $\cdot$ D. Tataru $\cdot$
}

E. A. Davies

Published online: 8 October 2014

(C) Springer Science+Business Media New York 2014

Erratum to: J Neurooncol

DOI 10.1007/s11060-014-1582-3

The second author's middle initial was incorrect in the original publication. It is correct in this erratum.

The online version of the original article can be found under doi:10.1007/s11060-014-1582-3.

T. Ratneswaren $(\varangle) \cdot$ E. A. Davies

Cancer Epidemiology and Population Health, Research

Oncology, King's College London, 3rd Floor, Bermondsey

Wing, Guy's Campus, London SE1 9RT, UK

e-mail: tratneswaren@nhs.net

R. H. Jack · D. Tataru - E. A. Davies

Public Health England, London Knowledge and Intelligence

Team, 2nd Floor, Skipton House, Section C, 80 London Road,

London SE1 6HL, UK 